\title{
Structure and diversity of zooplankton communities in four reservoirs with varying nutrient compositions in the Yangtze River Basin, China
}

\author{
Guangjun Lv \\ Fish breeding and healthy culture research center \\ Southwest University \\ Rongchong 402460, China \\ gjlv66@163.com
}

\begin{abstract}
A total of 147 zooplankton species were identified from
\end{abstract} four reservoirs. Protozoa and rotifers were the most abundant species recorded. The following fifteen species were common to all four reservoirs: six protozoan species, four rotifer species, three cladoceran species and two copepod species (accounting for $40.0 \%, 26.7 \%, 20.0 \%$, and $13.3 \%$ of the species common to all of the reservoirs, respectively). Zooplankton diversity was significantly higher $(p<0.01)$ in the Jinshahe reservoir than in the remaining three reservoirs, with a Shannon-Wiener index $(\mathrm{H})$ of 2.99 and a Simpson index (d) of 5.16. Zooplankton diversity in the Daoguanhe reservoir was the lowest of the four reservoirs (H $=1.80, \mathrm{~d}=2.48$ ); higher values were obtained for the Xujiahe $(\mathrm{H}$ $=2.08, d=3.58)$ and Taoyuanhe $(H=2.07, d=3.72)$ reservoirs. The Simpson indices of the Xujiahe and Taoyuanhe were significantly different from those of the Daoguanhe (all $p<0.05$ ). Protozoan and rotiferan biomasses were significantly positively correlated with COD, TN and TP $(p<0.01)$ and significantly negatively correlated with DO $(p<0.01)$. The cladoceran and copepod densities were low and highly variable, and they were not significantly correlated with COD, DO, TN or TP. The dominant species density was significantly correlated with zooplankton density. Zooplankton abundance was significantly negatively correlated with phytoplankton abundance in the Jinshahe but positively correlated in the Daoguanhe (correlation coefficient $r=0.45$ ); no significant correlations were observed in the remaining two reservoirs.

Key words-plankton; biodiversity index; biotic index; community structure; temporal and spatial variations; trophic types; reservoir

\section{I . INTRODUCTION}

Zooplankton represent a highly diverse and complex animal group. They participate in water circulation and energy flow and have strong metabolic activity. Through the direct ingestion of phytoplankton, zooplankton influence population and species dynamics; through excretion and secretion, they contribute to the decomposition and circulation of organic matter in aquatic ecosystems and stimulate algae growth. Because zooplankton are the prey for fish and other aquatic animals, they play an important role in aquatic ecosystems. Currently, zooplankton studies cover a wide range of topics, but they focus primarily on the spatial and temporal changes of colony structure [1-4], the influences of biotic or abiotic factors [5-7] or the nutritional quality of water [8-9]. These studies tend to not involve comparative investigations of different types of water systems, such as lakes. We compared the composition of zooplankton among four different types of reservoirs in Hubei Province, China. We recorded the biomass and density of the zooplankton species and several ecological variables to investigate zooplankton community structure, environmental influences on zooplankton and the interaction between zooplankton and phytoplankton. These results provide quantitative data regarding the aquatic environment of reservoirs, and the data can be used to assist in the management of reservoir fishery resources and inform environmental protection policies for aquatic ecosystems.

\section{II . MATERIALS AND METHODS}

\section{A. Sample collection sites}

Zooplankton samples were collected at the Jinshahe, 
Daoguanhe, Xujiahe and Taoyuanhe reservoirs over the following multiple sampling periods: November $4^{\text {th }}$ to $10^{\text {th }}$, 2006; February $2^{\text {nd }}$ to $8^{\text {th }}, 2007$; May $1^{\text {st }}$ to $7^{\text {th }}, 2007$; and August $4^{\text {th }}$ to $10^{\text {th }}, 2007$. The sampling stations were established at upstream, midstream and downstream sections of the reservoirs, and they are referred to as stations I, II and III, respectively. The station locations were recorded using a GPSI2 global positioning system. The four reservoirs are located in Hubei Province (between latitudes N30 $19^{\prime}$ $\mathrm{N} 32^{\circ} 9^{\prime}$ and longitudes $\left.\mathrm{E} 113^{\circ} 6^{\prime}-\mathrm{E} 115^{\circ} 0^{\prime}\right)$ and are among the mid- to large-sized reservoirs of the central YangtzeHe region. The Xujiahe reservoir has a volume of 778 million $\mathrm{m}^{3}$ and an area of $3813.3 \mathrm{hm}^{2}$; the Daoguanhe reservoir has a volume of 107 million $\mathrm{m}^{3}$ and an area of $500 \mathrm{hm}^{2}$, and the Jinshahe reservoir has a volume of 178.7 million $\mathrm{m}^{3}$ and an area of $1333.3 \mathrm{hm}^{2}$. These three reservoirs are hill reservoirs. The volume of the Taoyuanhe reservoir is 58.3 million $\mathrm{m}^{3}$, and its area is $389.0 \mathrm{hm}^{2}$; it is a valley reservoir.

\section{B. Collection methods and sample preparation}

Qualitative sample collection: a \#25 plankton net was used to collect protozoa and rotifers, and a \#13 plankton net was used to collect cladocerans and copepods. Quantitative sample collection: the same collection method was used for protozoa, rotifers and phytoplankton. To collect cladocerans and copepods, a 5-L Plexiglass water collector was used to obtain 10-L water samples at five depths: surface $(0.5 \mathrm{~m}$ below the water surface), SD, $2 \mathrm{SD}, 3 \mathrm{SD}$ and bottom $(0.5 \mathrm{~m}$ from the water bottom). The water samples were filtered through a \#25 plankton net, and the quantitative biota sample was stored and preserved in bottles that contained 3-5\% formaldehyde. The samples for live examination were stored in a 500-ml beaker. The samples were taken to the lab for species identification and quantitative analysis, and the densities (cells $\cdot \mathrm{L}^{-1}$ ) and biomasses $\left(\mathrm{mg} \cdot \mathrm{L}^{-1}\right)$ [10-13] were recorded.

\section{Hydrochemical factor analysis}

The determinations of COD, DO and TN were performed as previously described [14]. TP was determined using sulfuric acid nitrolysis.

\section{Data analysis}

The calculation of the zooplankton diversity index was performed using the Simpson diversity index (d) and the Shannon-Wiener diversity index (H) [15]:

$$
\begin{aligned}
& d=\frac{N(N \quad 1)}{s} \\
& n_{i}\left(n_{i} \quad 1\right) \\
& i 1 \\
& H{ }_{i=1}^{s} \quad n(N / 1) \mathrm{Q}_{i} \mathrm{~g}\left(n_{i} / N\right)
\end{aligned}
$$

where $S$ is the number of species in the sample, $n_{i}$ is the number or density of the $i$ th organism in the sample and $N$ is the total number or total density of the organisms in the sample.

We used SPSS13.0 and CCA software programs for the data analysis. Unless otherwise noted, the experimental data that were analyzed represent the arithmetic averages of the measured values from the corresponding reservoirs.

\section{RESULTS}

\section{A. Zooplankton species composition}

A total of 147 zooplankton species were identified from the four reservoirs; they represented 11 orders, 44 families and 87 genera. Forty-seven species $(32.0 \%)$ were protozoans, $43(29.3 \%)$ were rotifers, $35(23.8 \%)$ were cladocerans and 22 $(14.9 \%)$ were copepods. Therefore, protozoa and rotifers dominated the species composition. Ninety species were collected from the Jinshahe, 61 from the Daoguanhe, 76 from the Xujiahe and 73 from the Taoyuanhe. Fifteen species were found in all four reservoirs as follows: six protozoan species (40\% of species common to all four reservoirs), four rotifer species $(26.7 \%)$, three cladoceran species $(20.0 \%)$ and two copepod species $(13.3 \%)$.

\section{B. Zooplankton density and biomass}

1) Density and biomass by reservoir

The zooplankton densities in the four reservoirs decreased in the following order: Daoguanhe $>$ Xujiahe > Taoyuanhe > Jinshahe. Biomass exhibited a different pattern; it declined in the following order: Xujiahe > Daoguanhe > Taoyuanhe > Jinshahe. The zooplankton biomass in each reservoir and at 
each sampling site is shown in Table 1.

\section{2) Spatial and temporal variation in density and biomass}

The zooplankton biomass was significantly lower at depths of 3 SD or greater than at the surface, SD and 2 SD layers. Zooplankton biomass varied among the surface, SD and 2 SD layers. Upstream, the surface layer had the highest biomass, whereas at the mid- and downstream sites, the SD layer or the $2 \mathrm{SD}$ layer (depending on the reservoir) displayed the highest biomass. This variation among the sites may reflect biases in the sampling times; the sampling began in the upstream section and ended downstream. Although zooplankton exhibit phototaxis, they gather at subsurface depths under high light levels.

Zooplankton density decreased within the JinshaHe in the following order: midstream > upstream > downstream; in the remaining three reservoirs, density decreased from upstream to downstream. In all of the reservoirs, biomass also decreased from upstream to downstream. Zooplankton density declined seasonally in the following order: spring > summer > fall $>$ winter. Table 1 presents the density and biomass data by date and site.

Table 1 Horizontal distribution and seasonal changes in the density $\left(10^{3} \mathrm{ind} / \mathrm{L}\right)$ and biomass $(\mathrm{mg} / \mathrm{L})$ of plankton

\begin{tabular}{|c|c|c|c|c|c|c|c|c|c|}
\hline \multirow{2}{*}{ Reservoir } & \multirow{2}{*}{ Time } & \multicolumn{2}{|c|}{ Upstream } & \multicolumn{2}{|c|}{ Middle stream } & \multicolumn{2}{|c|}{ Downstream } & \multicolumn{2}{|c|}{ Average } \\
\hline & & Density & Biomass & Density & Biomass & Density & Biomass & Density & Biomass \\
\hline \multirow{5}{*}{ Jinshahe } & $06-11$ & 0.863 & 1.227 & 0.720 & 1.008 & 0.782 & 1.035 & 0.788 & 1.090 \\
\hline & $07-02$ & 0.967 & 1.459 & 0.919 & 1.296 & 0.874 & 1.139 & 0.920 & 1.298 \\
\hline & $07-05$ & 0.926 & 1.441 & 0.831 & 1.188 & 0.734 & 1.227 & 0.830 & 1.285 \\
\hline & $07-08$ & 1.025 & 1.283 & 1.404 & 1.202 & 0.897 & 1.147 & 0.988 & 1.211 \\
\hline & Average & 0.945 & 1.353 & 0.969 & 1.174 & 0.822 & 1.137 & 0.882 & 1.221 \\
\hline \multirow{5}{*}{ Daoguanhe } & $06-11$ & 1.156 & 2.039 & 1.102 & 2.009 & 1.079 & 1.789 & 1.113 & 1.964 \\
\hline & $07-02$ & 1.104 & 2.007 & 1.007 & 1.575 & 0.897 & 1.395 & 1.003 & 1.659 \\
\hline & 07-05 & 1.704 & 2.560 & 1.631 & 2.375 & 1.553 & 2.147 & 1.629 & 2.361 \\
\hline & $07-08$ & 1.391 & 2.356 & 1.290 & 2.036 & 1.213 & 1.763 & 1.298 & 2.052 \\
\hline & Average & 1.339 & 2.241 & 1.258 & 1.999 & 1.186 & 1.774 & 1.261 & 2.009 \\
\hline \multirow{5}{*}{ Xujiahe } & $06-11$ & 1.278 & 2.691 & 1.146 & 3.019 & 1.058 & 2.468 & 1.161 & 2.726 \\
\hline & $07-02$ & 1.309 & 2.717 & 0.981 & 2.405 & 0.903 & 2.204 & 0.947 & 2.442 \\
\hline & 07-05 & 1.433 & 2.807 & 1.201 & 2.260 & 0.989 & 1.876 & 1.207 & 2.315 \\
\hline & 07-08 & 1.075 & 2.411 & 0.950 & 2.124 & 0.876 & 1.896 & 0.967 & 2.143 \\
\hline & Average & 1.274 & 2.657 & 1.070 & 2.452 & 0.957 & 2.111 & 1.071 & 2.407 \\
\hline \multirow{5}{*}{ Taoyuanhe } & 06-11 & 1.216 & 2.271 & 1.109 & 2.521 & 1.079 & 1.962 & 1.135 & 2.251 \\
\hline & $07-02$ & 0.977 & 1.850 & 0.931 & 1.680 & 0.858 & 1.483 & 0.922 & 1.671 \\
\hline & $07-05$ & 1.345 & 1.834 & 1.160 & 1.599 & 1.059 & 1.535 & 1.188 & 1.656 \\
\hline & 07-08 & 0.914 & 2.202 & 0.812 & 1.974 & 0.726 & 1.814 & 0.817 & 1.997 \\
\hline & Average & 1.113 & 2.039 & 1.003 & 1.944 & 0.931 & 1.699 & 1.016 & 1.894 \\
\hline
\end{tabular}

\section{Composition of the dominant zooplankton species}

Dominant species were identified from the zooplankton density data [11]. As expected from the differences in geography and trophic structure among sampling locations, the dominant species also varied across locations; no single dominant species was common to all four reservoirs. Twelve dominant species were identified in the Jinshahe; they accounted for $13.3 \%$ of the total species in the reservoir. Eleven dominant species were identified in the Daoguanhe ( $18.0 \%$ of the total species). In the Xujiahe, 10 dominant species were identified (13.2\% of the total species). Eleven dominant species were identified in the Taoyuanhe $(15.1 \%$ of 
the total species).

\section{Zooplankton diversity}

The Shannon-Wiener $(\mathrm{H})$ and Simpson indices (d) of zooplankton diversity in each reservoir and the results of the statistical analysis are presented inTables 2 and 3.

E. Correlations between major physical and chemical

\section{indicators and zooplankton biomass}

We conducted regression statistics and analyses of variance to test for relationships between the biomasses of protozoa and rotifers and COD, DO, TN and TP (table 4 ). The biomasses of protozoa and rotifers were significantly positively correlated with COD, TN, and TP (all p < 0.01) and significantly negatively correlated with DO (both $\mathrm{p}<0.01$ ).

Table 2 Diversity index and horizontal distribution of zooplankton (Mean \pm SD)

\begin{tabular}{|c|c|c|c|c|c|}
\hline \multirow{2}{*}{ Reservoir } & \multirow{2}{*}{ Index } & \multicolumn{3}{|c|}{ Sampling spot } & \multirow{2}{*}{ Average } \\
\hline & & I & II & III & \\
\hline \multirow{2}{*}{ Jinshahe } & $H^{\prime}$ & $3.13 \pm 0.32^{\mathrm{a}}$ & $3.02 \pm 0.29^{\mathrm{a}}$ & $2.82 \pm 0.25^{\mathrm{a}}$ & $2.99 \pm 0.30^{\mathrm{a}}$ \\
\hline & $d$ & $5.37 \pm 1.32^{\mathrm{a}}$ & $5.19 \pm 1.17^{\mathrm{a}}$ & $4.91 \pm 1.06^{\mathrm{a}}$ & $5.16 \pm 1.17^{\mathrm{a}}$ \\
\hline \multirow{2}{*}{ Daoguanhe } & $H^{\prime}$ & $2.03 \pm 0.27^{\mathrm{a}}$ & $1.82 \pm 0.26^{\mathrm{ab}}$ & $1.55 \pm 0.22^{\mathrm{b}}$ & $1.80 \pm 0.26^{\mathrm{b}}$ \\
\hline & $d$ & $2.74 \pm 0.61^{\mathrm{a}}$ & $2.44 \pm 0.53^{\mathrm{a}}$ & $2.25 \pm 0.47^{\mathrm{a}}$ & $2.48 \pm 0.55^{\mathrm{b}}$ \\
\hline \multirow{2}{*}{ Xujiahe } & $H^{\prime}$ & $2.09 \pm 0.21^{\mathrm{a}}$ & $2.19 \pm 0.22^{\mathrm{a}}$ & $1.97 \pm 0.21^{\mathrm{a}}$ & $2.08 \pm 0.21^{\mathrm{b}}$ \\
\hline & $d$ & $3.57 \pm 0.47^{\mathrm{a}}$ & $3.71 \pm 0.59^{\mathrm{a}}$ & $3.46 \pm 0.39^{\mathrm{a}}$ & $3.58 \pm 0.49^{\mathrm{c}}$ \\
\hline \multirow{2}{*}{ Taoyuanhe } & $H^{\prime}$ & $2.14 \pm 0.17^{\mathrm{a}}$ & $2.09 \pm 0.22^{\mathrm{a}}$ & $2.00 \pm 0.15^{\mathrm{a}}$ & $2.07 \pm 0.17^{\mathrm{b}}$ \\
\hline & $d$ & $3.79 \pm 0.62^{\mathrm{a}}$ & $3.76 \pm 0.59^{\mathrm{a}}$ & $3.61 \pm 0.54^{\mathrm{a}}$ & $3.72 \pm 0.58^{\mathrm{c}}$ \\
\hline
\end{tabular}

Table 3 Seasonal changes in the zooplankton diversity index (Mean \pm SD)

\begin{tabular}{|c|c|c|c|c|c|c|}
\hline \multirow{2}{*}{ Reservoir } & \multirow{2}{*}{ Index } & \multicolumn{4}{|c|}{ Time } & \multirow{2}{*}{ Average } \\
\hline & & 2006-11 & $2007-2$ & $2007-5$ & $2007-8$ & \\
\hline \multirow{2}{*}{ Jinshahe } & $H^{\prime}$ & $2.90 \pm 0.30^{\mathrm{ab}}$ & $2.45 \pm 0.25^{\mathrm{b}}$ & $3.36 \pm 0.34^{\mathrm{a}}$ & $3.25 \pm 0.32^{\mathrm{ab}}$ & $2.99 \pm 0.31^{\mathrm{a}}$ \\
\hline & $d$ & $5.09 \pm 1.51^{\mathrm{ab}}$ & $4.53 \pm 1.08^{\mathrm{b}}$ & $5.52 \pm 1.73^{\mathrm{a}}$ & $5.48 \pm 1.62^{\mathrm{a}}$ & $5.16 \pm 1.56^{\mathrm{a}}$ \\
\hline \multirow{2}{*}{ Daoguanhe } & $H^{\prime}$ & $1.75 \pm 0.22^{\mathrm{ab}}$ & $1.59 \pm 0.15^{\mathrm{b}}$ & $1.89 \pm 0.19^{\mathrm{ab}}$ & $1.96 \pm 0.26^{\mathrm{a}}$ & $1.80 \pm 0.18^{\mathrm{b}}$ \\
\hline & $d$ & $2.38 \pm 0.51^{\mathrm{ab}}$ & $2.18 \pm 0.47^{\mathrm{b}}$ & $2.56 \pm 0.69^{\mathrm{ab}}$ & $2.79 \pm 0.77^{\mathrm{a}}$ & $2.48 \pm 0.62^{\mathrm{b}}$ \\
\hline \multirow{2}{*}{ Xujiahe } & $H^{\prime}$ & $2.25 \pm 0.26^{\mathrm{a}}$ & $1.75 \pm 0.18^{\mathrm{a}}$ & $1.96 \pm 0.23^{\mathrm{a}}$ & $2.38 \pm 0.27^{\mathrm{a}}$ & $2.08 \pm 0.23^{b}$ \\
\hline & $d$ & $3.79 \pm 0.53^{\mathrm{ab}}$ & $3.02 \pm 0.42^{\mathrm{b}}$ & $3.37 \pm 0.45^{\mathrm{ab}}$ & $4.14 \pm 0.59^{\mathrm{a}}$ & $3.58 \pm 0.47^{\mathrm{c}}$ \\
\hline \multirow{2}{*}{ Taoyuanhe } & $H^{\prime}$ & $2.11 \pm 0.19^{\mathrm{a}}$ & $1.77 \pm 0.15^{\mathrm{a}}$ & $2.26 \pm 0.26^{\mathrm{a}}$ & $2.16 \pm 0.22^{\mathrm{a}}$ & $2.07 \pm 0.20^{\mathrm{b}}$ \\
\hline & $d$ & $3.70 \pm 0.73^{\mathrm{ab}}$ & $3.36 \pm 0.54^{\mathrm{b}}$ & $4.07 \pm 079^{\mathrm{a}}$ & $3.74 \pm 0.73^{\mathrm{ab}}$ & $3.72 \pm 0.73^{\mathrm{c}}$ \\
\hline
\end{tabular}

Table 4 Water quality of the four investigated reservoirs

\begin{tabular}{ccccc}
\hline Index & Jinshahe & Daoguanhe & Xujiahe & Taoyuanhe \\
\hline DO (mg/L) & 8.959 & 7.026 & 7.917 & 8.083 \\
TN (mg/L) & 0.392 & 1.018 & 0.970 & 0.704 \\
TP (mg/L) & 0.012 & 0.042 & 0.03 & 0.011 \\
COD (mg/L) & 3.505 & 9.166 & 5.022 & 5.171 \\
\hline
\end{tabular}

\section{DISCUSSIN}

\section{A. Influence of zooplankton on nutrient levels}

Zooplankton abundance is limited by nutrient availability.
In general, increased nutrient levels and primary productivity lead to increases in zooplankton abundance [16]. In the present study, we observed positive correlations between nutrient levels and zooplankton abundance. In the Jinshahe reservoir, which contained moderate nutrient levels, the density and biomass of zooplankton were $0.883 \mathrm{ind} / \mathrm{L}$ and $1.221 \mathrm{mg} / \mathrm{L}$, respectively. In contrast, in the nutrient-rich Daoguanhe reservoir, the density and biomass of zooplankton were $1.261 \mathrm{ind} / \mathrm{L}$ and $2.009 \mathrm{mg} / \mathrm{L}$, respectively. The Xujiahe and Taoyuanhe reservoirs had intermediate nutrient levels; 
their zooplankton densities were $1.071 \mathrm{ind} / \mathrm{L}$ and 1.016ind/L, respectively, and their zooplankton biomasses were 2.497 $\mathrm{mg} / \mathrm{L}$ and $1.894 \mathrm{mg} / \mathrm{L}$, respectively. We also found correlations between measures of zooplankton abundance and specific nutrients. The biomasses of the protozoa and rotifers were significantly and positively correlated with TN, TP, and COD (all p < 0.01), and they were significantly negatively correlated with DO (both $\mathrm{p}<0.01$ ). In contrast, the density and biomass of the cladocerans were uncorrelated with either TN, TP, COD or DO. Small correlation coefficients were obtained when copepod abundance was correlated with TN, TP, COD and DO values. This latter finding is inconsistent with Wang's (2008) [17] study of 27 sub-tropical lakes. The author reported significant positive correlations between zooplankton (planktonic crustaceans, cladocerans and copepods) biomass and TP. The differences between the two studies may reflect differences in the ecologies of the reservoirs and lakes that were studied. In addition, in the Wang [17] study, the total number of zooplankton species was significantly and negatively correlated with TN, TP, NH4-N, NO3-N and COD. Jun Jiang et al. (2008) [18] reported a significant negative correlation between the total number of zooplankton species and the concentration of $\mathrm{NO}_{2}-\mathrm{N}$, a significant negative correlation between the total number of creeping ciliates and the $\mathrm{NO}_{2}-\mathrm{N}$ or $\mathrm{NO}_{3}-\mathrm{N}$ concentration, and a significant positive correlation between the total number of swimming and fixed ciliates and the $\mathrm{NO}_{3}-\mathrm{N}$ concentration. These results indicate that the nutrient level strongly influences zooplankton density and biomass. It has been proposed that TP may be used to predict zooplankton biomass [17].

The Jinshahe reservoir had the highest diversity index $(\mathrm{H}$ $=2.99, \mathrm{~d}=5.16)$ of the four reservoirs, and the Daoguanhe reservoir had the lowest diversity index $(H=1.80, d=2.48)$. Intermediate values were obtained for the Xujiahe $(\mathrm{H}=2.08$, $\mathrm{d}=3.58)$ and Taoyuanhe reservoirs $(\mathrm{H}=2.07, \mathrm{~d}=3.72)$. The Shannon-Wiener $(\mathrm{H})$ and Simpson $(\mathrm{d})$ indices can be used to indicate water quality as follows: $\mathrm{H}>3$ (or $\mathrm{d}>6$ ) indicates clean water, $3>\mathrm{H}>2$ (or $6 \geq \mathrm{d} \geq 3$ ) indicates slight contamination, $2>\mathrm{H}>1$ (or $3 \geq \mathrm{d} \geq 2$ ) indicates moderate contamination and $1>\mathrm{H}>0$ (or $\mathrm{d}<2$ ) indicates heavy contamination. According to these indicators, the water quality of the Jinshahe reservoir is high; the Xujiahe and Taoyuanhe reservoirs are slightly contaminated, and the Daoguanhe reservoir is moderately contaminated. These results are consistent with phytoplankton and comprehensive trophic state indices (TSIc). Xie et al. (1996) [19] showed that the species diversities of copepods and rotifers responded differently to water nutrient levels; when the levels changed from nutrient-moderate to nutrient-rich, the species diversity decreased (i.e., nutrient enrichment decreased zooplankton diversity). Because contamination-resistant species in nutrient-rich water can become dominant, the growth of other species can be inhibited, which can decrease diversity. However, many researchers warn against using the zooplankton diversity index as a measure of water quality and have indicated the drawbacks of using the Shannon-Wiener (H) and Simpson (d) indices to calculate zooplankton diversity [20-22]. Brachionus calyciflorus, Asplanchna brightwelli, Mesocyclops leuckarti and other species were widely distributed in the nutrient-rich Daoguanhe reservoir and became the dominant species, which suggests that they may possibly be used as contamination indicator species.

\section{B. Effects of zooplankton and nutrient levels on phytoplankton biomass}

Zooplankton influence the phytoplankton community structure in two main ways: by foraging on phytoplankton and by altering nutrient circulation [23]. Zooplankton forage on phytoplankton selectively according to factors such as phytoplankton particle size and cell abundance. The proportion of inedible algae in the community can affect the extent to which zooplankton alter phytoplankton community structure [24]. Zooplankton impose several indirect effects on phytoplankton. One such effect arises through feeding on phytoplankton because this activity reduces competition among phytoplankton (fewer phytoplankton species persist). Another effect involves the secretions and waste products of zooplankton, which regenerate nutrients. Nutritional masses that are released by zooplankton form nutrient blocks in the water column [25], and they then increase phytoplankton diversity by increasing spatial heterogeneity. With respect to density, our data suggest that zooplankton inhibit phytoplankton in the Jinshahe; in November 2006, the 
phytoplankton density was $118.6 \times 10^{4}$ cells/L, but the zooplankton density was only $0.788 \times 10^{3}$ ind/L. In May 2007, the zooplankton density reached $0.823 \times 10^{3} \mathrm{ind} / \mathrm{L}$, whereas the phytoplankton density reached $158.4 \times 10^{4}$ cells/L. By August 2007, the zooplankton density had increased to 0.988 $\times 10^{3}$ ind/L, whereas the phytoplankton density had decreased to $135.3 \times 10^{4}$ cells/L. However, a different pattern was observed in the Daoguanhe; this trend suggests a slight positive relationship between zooplankton and phytoplankton density. From February to May 2007, the zooplankton density in the Daoguanhe increased from $1.003 \times 10^{3} \mathrm{ind} / \mathrm{L}$ to $1.629 \times$ $10^{3} \mathrm{ind} / \mathrm{L}$, and the phytoplankton density also increased from $199.1 \times 10^{4}$ cells/L to $341.3 \times 10^{4}$ cells/L. In August 2007 , the zooplankton density decreased to $1.298 \times 10^{3} \mathrm{ind} / \mathrm{L}$, and the phytoplankton density also decreased (to $248.6 \times 10^{4}$ cells/L). In the Xujiahe and Taoyuanhe, the apparent effect of zooplankton density on algal density was slightly stronger but still weak. This result may be related to the nutritional structure of the water body. Water bodies that contain different nutrient levels have different algal community structures. Elser et al. (1991) [26] found that zooplankton had weak inhibitory effects on phytoplankton in oligotrophic or eutrophic lakes, whereas in mesotrophic or meso- to eutrophic lakes, zooplankton had stronger inhibitory effects. Phytoplankton biomass decreased in the following order: Jinshahe $(0.95)>$ Xujiahe $(0.88)>$ Taoyuanhe $(0.61)>$ Daoguanhe (0.60). The capacity for algae utilization by zooplankton was the lowest in the Daoguanhe and Taoyuanhe. This finding suggests that only a portion of the algae in the phytoplankton (primarily micro-algae) can be exploited by zooplankton. Songbo Wang (2008) [17] proposed that changes in the micro-phytoplankton biomass were likely important in decreasing the efficiency of energy transfer. Nutrients are the physical basis for zooplankton survival and reproduction. Based on Liebig's Law of the Minimum, nitrogen and phosphorus are the major limiting factors in phytoplankton growth. However, in some cases, differences in the proportions and ratios of nutrients that are absorbed by phytoplankton can inhibit phytoplankton growth. Suttle and Harrison (1987) [27] argued that nitrogen limitation was often associated with eutrophication. In general, as water nutrient levels increase, phytoplankton biomass also increases.
Zooplankton can also be limited by nutrients. In all four of the reservoirs that we investigated, we found a tendency for the zooplankton and phytoplankton biomasses to increase with the water nutrient levels.

\section{ACKNOWLEDGEMENT}

Funding for this study was provided by the Southwest University Ph.D. Fund(2010BSr06).

\section{REFERENCES}

[1] Nogueira M G. Phytoplankton composition, dominance and abundance as indicators of environmental compartmentalization in the Jurumirim reservoir (ParanapanemaHe), Sao Paulo, Brazil. Hydrobiologia, 2000, 431: 115-128.

[2] Lu J R, Li D S, Chou C S. Studies of the large- and mid-sized reservoirs of Shandong Province - I . Zooplankton ecology. Journal of ocean University of Qingdao, 1994, 24(1): 33-39.

[3] Chen M R. Effect of a mixed culture of silver carp (Hypophthalmichthys molitrix) and Nile tilapia (Oreochromis nilotica) on a zooplankton community in a tropical reservoir: A large enclosure experiment. Thesis for master of science. Huazhong Agricultural University. Wuhan, 2007.

[4] Zhao S Y. Han B P. Size structure of the metazoan zooplankton community in a tropical lake: Xinghu Lake, South China. Acta Ecologica Sinces, 2006, 26(8): 2646-2654.

[5] Sommer U, Sommer F, Santer B, Zöllner E, et al. Daphnia versus copepod impact on summer phytoplankton: functional compensation at both trophic levels. Oecologia, 2003, 135: 639-647.

[6] Andersen T, Hessen D O. Carbon, nitrogen and phosphorus content of freshwater zooplankton. Limnology and Oceanography, 1991, 36(4): 807-817.

[7] Sterner R W, Elser J J, Hessen D O. Stoichiometric relationships among producers, consumers and nutrient cycling in pelagic ecosystems. Biogeochemistry, 1992, 17: 49-67.

[8] Sprules W G, Munawar M. Plankton size spectra in relation to ecosystem productivity, size and perturbation. Can. J. Fish. Aquat. Sci. 1986, 43: 1789-1794.

[9] He Z H. A trophic classification of the lakes and reservoirs in China. Journal of Dalian Fisheries University, 1987, 1: 1-10.

[10] Jiang X Z. Du N S. Fauna Sinica, Crustacea, Freshwater Cladocera. Beijing: Science press. 1979. 
[11] Zhang Z S, Huang X F. Methods for the study of freshwater plankton. Beijing: Science press. 1991.

[12] Chen X M. Biomass calculation of freshwater copepoda. Acta Hydrobiologica Sinica, 1981, 7(3): 397-408.

[13] Huang X F. Methods for the quantification of freshwater zooplankton. Reservoir fisheries, 1982, 4: 52-58.

[14] National environmental protection bureau. A guide to analytical methods of water monitoring and waste water. Beijing: China environmental science press, 2002.

[15] Shannon C E, Wiener W J. The mathematical theory of communication, University of Illinois, Urbana. 1949. 117.

[16] Lin Q Q, Hu R, Duan S S. Reservoir trophic states and the response of plankton in Guangdong Province. Acta Ecologica Sinces, 2003, 23(6): 1101-1108.

[17] Wang S B. Studies of zooplankton ecology in the shallow lakes of the middle and lower reaches of the YangtzeHe. [Doctoral Dissertation]. Wuhan: Institute of hydrobiology Chinese Academy of Sciences, 2008

[18] Jiang J, Li H z, Li X Y. Characteristics of zooplankton communities in the biological grid devica controlling. Shanghai Chemical Industry, 2008, 33(5): 1-5.

[19] Xie P, Zhu G Y, Dai M, et al. Impacts of eutrophication on biodiversity of plankton community. Acta Hydrobiolog Sinica, 1996, 20(Suppl): 30-37.
[20] $\mathrm{Hu} \mathrm{C}$ Y. Investigation of planktonic rotifers in Baoan Lake, Hubei Province Acta Hydrobiolog Sinica, 2000, 24(5): 426-429.

[21] Li G G, Yu Z M. Community structure of zooplankton in Lake Qiandaohu. Acta Ecologica Sinces, 2002, 22(2): 156-162.

[22] Gilbert J J. Suppression of rotifer populations by Daphnia: A review of the evidence, the mechanisms, and the effects on zooplankton community structure. Limnol Oceanogr, 1988a, 33(6): 1286-1303.

[23] Bell T. The ecological consequences of unpalatable prey: phytoplankton response to nutrient and predator additions. Oikos, 2002, 99(1): 59-68.

[24] Lehman J T. Selective herbivory and its role in the evolution of phytoplankton growth strategies. Michigan Univ, Ann Arbor (USA), 1986.

[25] Elser J J, Urabe J. The stoichiometry of consumer-driven nutrient recycling: theory, observations, and consequences. Ecology, 1999, 80, 735-751.

[26] Suttle C A, Harrison P J. Ammonium and phosphate uptake rates, $\mathrm{N}$ : $\mathrm{P}$ supply ratios, and evidence for $\mathrm{N}$ and $\mathrm{P}$ limitation in some oligotrophic lakes. Limnol. Oceanogr, 1987, 33: 186-202. 